\title{
As audiografias: uma conversa histórica através dos sons
}

\section{The audiografias: a historical conversation through sounds}

\author{
Luiz Otávio Corrêa* \\ lo.correa@hotmail.com
}

Resumo

Este artigo pretende apresentar o que se chama de Audiografias, escritas históricas produzidas a partir da linguagem radiofônica. Para explicar melhor a proposta, foi necessário relacionar a História Pública, ponto de partida desta experiência, ao paradigma relacional da comunicação. Finalmente, é apresentada uma primeira produção chamada "O Rádio e o poder nos anos 30", bem como a página Paisagens Históricas, espaço para a distribuição e para as interações realizadas pelo programa produzido.

Palavras-chave: Audiografias, Paradigma relacional, Comunicação, História Pública,

\begin{abstract}
This article is intended to present what we call Audiografias, historical writings produced from the radio language. In order to better explain the proposal was necessary to relate the Public History, starting point for this experience, to the relational paradigm of communication. Finally been presented a first production called "The Radio and the power in the 30" as well as Paisagens Históricas, space for the distribution and interactions performed by the program produced.
\end{abstract}

Keywords: Audiografias, Relational paradigm, Comunication, Public History. 


\section{Introdução}

Este artigo levanta a possibilidade da produção de documentos históricos por meio de uma escrita sonora, alargando os espaços de recepção tradicionais da História. De maneira experimental, propõe-se a construção de arquivos sonoros que se traduzam no alargamento das possiblidades da produção histórica, seus objetos e temas, pela edição de sons, músicas, depoimentos e pesquisas disponibilizadas em vários suportes na internet, em arquivos públicos e de rádios.

A linguagem radiofônica tem muito a colaborar com História Pública e vice-versa. Eles nasceram para realizar um mesmo movimento. A História Pública quer conversar, quer fazer comunicação.

Neste artigo, de uma maneira geral, pretende-se discutir o que é a comunicação e sua relação com o fazer histórico de maneira pública, propondo uma experiência que chamaremos de Audiografias. Nesta proposta, estas produções partem da linguagem radiofônica, mas vão além dela, rompendo com a lógica da rádio comercial.

$\mathrm{Na}$ sequência apresentada aqui, se discute a relação entre o conceito de comunicação, proposto por José Luis Braga e Vera França, com o de História Pública. Em segundo lugar, procura-se discutir como as novas tecnologias da informação e da comunicação alimentam as interações entre o ouvinte e o leitor de História.

No terceiro momento, pretende-se discutir a questão das fontes para a produção destas produções, retomando as experiências da História Oral e também as possíveis utilizações de registros históricos nos vários bancos de sons. Por último, pretende-se apresentar uma proposta experimental, sua página na internet e as interações possíveis.

\section{A comunicação e a história: a questão da audiência}

Os estudos da pesquisadora Vera Veiga França (2001) nos permitem abrir um diálogo importante. Para ela, na comunicação existem dois objetos: os meios de comunicação e o processo comunicacional. Em relação ao primeiro objeto, ela diz:

De um lado, e de forma mais evidente, o objeto recortado são os meios de comunicação de massa (formulação mais antiga) ou a mídia - designação contemporânea, mais ampla, e que retira a ambigüidade do qualificativo "massa" (ênfase na amplitude do público atingido), referindo-se à comunicação realizada ou mediada pelas novas tecnologias (França, 2001, s.p).

Trata-se aqui, portanto, do estudo dos meios de comunicação e de sua indústria: a imprensa no século XIX, a televisão, as redes virtuais e o rádio, mídia que nos interessa aqui. No entanto, ela nos chama a atenção para o fato de que se ater apenas aos meios de comunicação não nos permitiria pensar nas mais variadas e complexas práticas comunicativas que realizamos todos os dias, para além logicamente dos meios de comunicação, mas também tendo eles como mediadores. Segundo ela:

Fechar o objeto da comunicação no campo das mídias é uma operação redutora, ao excluir as inúmeras práticas comunicativas que edificam e marcam a vida social - e não passam pelo terreno das mediações tecnológicas (por exemplo, o rumor, as relações de vizinhança e suas formas comunicativas, os teatros ou encenações urbanas - entre outras) (França, 2001, op.cit.).

Pensando na comunicação como uma prática, França faz refletir, nós historiadores também, sobre a questão da interdisciplinaridade dos estudos, tanto na comunicação quanto na História. Para estes, tal como para os antropólogos e para os próprios comunicólogos, as práticas sociais (ou comunicativas) são importantes pontos de partida. A comunicação nasceu interdisciplinar e a História também nunca deixou de ser.

Para explicar este movimento, França realiza uma retomada das principais escolas que influenciaram os estudos dos comunicólogos, apresentando suas importantes escolas: a Escola de Frankfurt, a Análise do Discurso, os Estudos Culturais nos anos 1960, a Teoria da Recepção na América Latina, dentre outras. Todas estas guardavam sua relação com outras áreas do conhecimento, como a antropologia, a filosofia e a sociologia. Para França, isto coloca a comunicação numa posição privilegiada, ao conseguir transgredir as fronteiras 
disciplinares. No entanto, ela se pergunta qual é a especificidade dos estudos de comunicação, a mesma que poderíamos fazer para nós historiadores. Para ela:

a comunicação compreende um processo de produção e compartilhamento de sentidos entre sujeitos interlocutores, realizado através de uma materialidade simbólica (da produção de discursos) e inserido em determinado contexto sobre o qual atua e do qual recebe os reflexos, (França, 2001,op.cit.).

Nesta perspectiva, é importante pensar nos processos de troca comunicacionais e não nos processos de transmissão. Por outro lado, os interlocutores não são meros receptores, mas produtores de discursos, como agentes sociais. O processo de produção de sentido é, neste aspecto, dialógico. Em vez de observar um evento de maneira isolada, os processos comunicacionais são observados em determinadas situações de fala, o que para os historiadores é um dado importante.

Segundo ela, finalmente, a especificidade do olhar comunicacional seria "alcançar a interseção de três dinâmicas básicas: o quadro relacional (relação dos interlocutores); a produção de sentidos (as práticas discursivas); a situação sócio-cultural (o contexto).” (França, op.cit.).

Ao analisar um programa de rádio, por exemplo, deve se observar os processos e as mediações construídas socialmente pelos vários interlocutores, a maneira que se produz e também em que situação esta produção se dá. Um programa de rádio é parte de um contexto sociocultural de múltiplas interações comunicacionais.

Vera França nos permite fazer História Pública, ao que parece. Mas o que nos faria diferente? Quais as especificidades do Historiador? Qual seria o nosso olhar específico?

\section{A História Pública e as práticas comunicativas}

A História Pública vem se consolidando, tanto no Brasil quanto internacionalmente, como um novo caminho para se pensar a produção historiográfica.

Segundo Rabelo e Rovai, “a História Pública é um novo caminho de conhecimento e prática de como se fazer História" que permite a reflexão sobre o trabalho do historiador. De maneira que a "História Pública é uma possibilidade não apenas de conservação e divulgação da história, mas de construção de um conhecimento pluridisciplinar atento aos processos sociais, às suas mudanças e tensões" (Rabelo e Rovai, 2011).

Novamente aqui, a aproximação com outras áreas do conhecimento, no nosso caso com a comunicação. Por outro lado, a História Pública propõe-se a pensar os processos sociais, os lugares de fala, o contexto de produção do discurso. Poderíamos retomar a questão do campo (THOMPSON, 2001), no qual a circunstância da ação estabelece relações de poder e são elementos importantes tanto para os historiadores quanto para os comunicólogos. Por outro lado, A História Pública produz para as grandes audiências, como aponta Evans:

Public History is history that is seen, heard, read, and interpreted by a popular audience. Public historians expand on the methods of academic history by emphasizing non-traditional evidence and presentation formats, reframing questions, and in the process creating a distinctive historical practice....Public history is also history that belongs to the public. By emphasizing the public context of scholarship, public history trains historians to transform their research to reach audiences outside the academy. (in: Evans, 2000).

De tal maneira que poderíamos acrescentar a estas propositivas acima a questão de que a História Pública pretende-se como uma prática comunicativa, uma conversa no sentido que os comunicólogos entendem e que, do ponto de vista epistemológico, é muito fértil para nós historiadores. Para José Luis Braga:

A questão da interação social vai além da metáfora conversacional (...) A conversação enfatiza os processos de ida-evolta, na troca entre interlocutores. A ideia de "resposta" é percebida como um retorno imediato ao ponto de origem da primeira contribuição conversacional (Braga, 2011).

A História descobriu a interlocução ao se chamar de Pública. Pode-se dizer que o faz como um exercício, ela quer conversar, alimentar as possibilidades de se tornar mediadora de processos conversacionais, 
Artigos

quer fazer comunicação. A História quer discutir as representações e as práticas produzidas pelo homem nas suas variadas temporalidades, mas quer também que conhecimento chegue ao grande público.

Pensar a História como uma conversa implica visualizar os interlocutores como agentes do ato deste processo e não somente receptores passivos dos vários textos produzidos pelo Historiador Público. Pensar nos leitores desta maneira significa criar redes de conversa, mediações que contribuem para produção e também para a circulação de toda esta produção simbólica.

De tal maneira que, hipoteticamente, poderíamos sugerir que os agentes produtores das escritas históricas, desta maneira aqui, prefiram a participação ativa dos interlocutores do processo de construção. É uma pergunta que poderíamos tentar responder em outro trabalho.

Mas cabe-nos perguntar agora como poderíamos pensar nas especificidades do fazer Histórico, qual o olhar nosso sobre toda esta interdisciplinaridade. O que justificaria dizer que fazemos História e não Comunicação. Mais uma vez, o paradigma conversacional poderia nos iluminar neste aspecto.

O historiador produz, tal como o músico e o produtor midiático. A maneira como isto pode ser feito é que precisa ser pensada, acredito, diferenciando o trabalho do historiador daquela perspectiva que trata a produção historiográfica como um produto midiático comercial, que tem que disputar o mercado de bens simbólicos.

Para Sara Albieri, (2011), a História Pública pode ser capaz de, por meio da consciência histórica, superar o conflito entre o fazer histórico e os limites impostos pela indústria de entretenimento, que condiciona trabalho do historiador ao produto midiático.

Desta tal maneira que, em vez da perspectiva comercial, adotada por alguns escritores e jornalistas, poderíamos pensar em outras formas de produção que mantenha tanto a independência do historiador em relação ao mercado quanto a legitimidade da produção historiográfica. Desta forma, o grande desafio é encontrar formatos que possam se transformar em caminhos alternativos a estes produtos sem, no entanto, direcionarmos para a lógica de mercado de bens simbólicos, simplesmente. E as Novas Tecnologias da Informação e da Comunicação podem nos ajudar muito neste processo.

\section{A linguagem do rádio e as novas possibilidades mediadoras}

Desde que se transformou em meio de comunicação eletrônico importante, o rádio tornou-se um dos baluartes da modernidade. Nesta perspectiva, acompanhou um movimento em direção à individualização da sociedade que Norbert Elias chamou de balança eu-nós. Associado ao capitalismo, ele foi ganhando forma e linguagem. Se isto possibilitou o seu desenvolvimento, também dificultou, de certa forma, que ele pudesse ter autonomia em relação ao mercado, associando-se cada vez mais à indústria cultural.

Segundo Patrick Charaudeau, o rádio é, dentre as mídias, "aquela que melhor faz coincidir o tempo da escuta com o tempo dos acontecimentos, o que faz do rádio a mídia do tempo presente" (Charaudeau, 2006). Enquanto um meio de comunicação eletrônico moderno, os radialistas atuam essencialmente em uma dimensão temporal de curtíssima duração, a dimensão do evento ou do fato. Segundo Eduardo Meditsch, o rádio:

É um meio de comunicação sonoro, invisível e que emite em tempo real. Se não for feito de som não é rádio, se tiver imagem junto não é mais rádio, se não emitir em tempo real (o tempo da vida real do ouvinte e da sociedade em que está inserido) é fonografia, também não é rádio (Meditsch, 1999, s.p.).

Por outro lado, o rádio comercial inserido na lógica e na dinâmica capitalista reproduz uma noção de tempos sem mudanças, a não ser aquela do evento. Enquanto indústria midiática produtora de bens simbólicos, o rádio contribui, de certa forma, para a ritualização do consumo, da mesma forma que os shopping centers, como também demonstra os trabalhos de Marinalva Barbosa sobre os meios de comunicação:

Constrói-se dois arquivos para o presente e a para o futuro e os meios de comunicação se constituem não apenas em arquivos para o futuro, mas em arquivos permanentes do presente. E a narrativa não é mais apenas a mescla do ficcional com o informacional, mas a narrativa histórica do imediato (Barbosa, 2004, p. 11). 
De maneira que há um processo de presentificação do tempo que se manifesta pelas comemorações oficiais, em que as informações são difundidas como espetáculo. "Para isso, mistura-se o presente e o passado, razão pela qual tornam os meios de comunicação verdadeiros guardiões das comemorações contemporâneas e construtores de uma dada materialização da memória" (Barbosa, op.cit).

O tempo ordinário e o imediatismo oralizado do rádio, em primeira instância, coloca-o como uma mídia do tempo sem tempo, uma dimensão linear, uma sequência dos fatos e de eventos que são dados como realidade. Eis o primeiro desafio ao historiador que trabalha numa outra dimensão temporal, nas suas múltiplas temporalidades.

No entanto, o rádio, como um fenômeno social, modifica e é modificado pela sociedade e pelo contexto histórico. A mudança no suporte modifica a relação entre as suas audiências e as indústrias midiáticas, criando uma segmentação do mercado de bens simbólicos, como demostrou os estudos de Burke e Briggs(2004). Com o advento da TV, “o rádio perdeu sua centralidade, mas ganhou em penetrabilidade e flexibilidade, adaptando modalidades e temas ao ritmo da vida cotidiana das pessoas". (Castells, 2001). A TV se tornou hegemônica, mas o rádio transformou-se em um instrumento midiático das comunidades ${ }^{1}$.

Quando ocorreu o processo de convergência da rádio para a internet, inaugurou-se um novo momento. Está em processo uma confluência entre as mídias e os sistemas de comunicação que permitiram o aparecimento de novas experiências midiáticas. O interessante é que todo este processo fez aparecer mídias híbridas, causando até certa dificuldade de definir o que são, devido à rapidez com que ganham espaço e muitas vezes desaparecem rapidamente. Atualmente, o streaming pode ser produzido por qualquer pessoa em sites que disponibilizam este serviço ${ }^{2}$. Neste contexto, desenvolvem, ainda que de forma transitória, as chamadas webrádios, as rádios on-line, os podcasts, dentre outras formas estudadas exaustivamente por estudiosos (as) como Nair Prata. (2009)

O mais importante é que toda esta transformação vem acompanhada do surgimento de comunidades virtuais que fazem emergir novas formas de sociabilidade. (Castells, 2001) Desta maneira, ocorre, ao mesmo tempo, um processo de individualização, acompanhado do aparecimento de redes de sociabilidade cada vez maiores complexas e interacionais através de fóruns, chats, blogs, etc.

Alex Primo, em artigo de 2005, demonstra que o podcast, por exemplo, quebra sincronia entre o tempo de produção e o tempo de escuta. Tal como os blogs, o podcast reorganiza a divisão do trabalho nas empresas de comunicação e permitem outro tipo de enunciação. Para este autor, por se tratar de uma mídia de nicho, eles "atingem públicos pequenos, mas que são interconectados entre si” (Primo, 2005, pg.10). Estas mídias, produzidas pelos mais variados interlocutores, dependem de maneira substantiva, das relações entre as instâncias de produção e recepção, nas suas interações mútuas.

No entanto, na perspectiva de Charaudeau, a oralidade do rádio cria uma relação de intimidade que vai se concretizar não somente na fala do locutor, que realiza uma "enunciação interpelativa", mas também através dos canais de interação com o ouvinte: o telefone, o correio eletrônico, as mensagens instantâneas. Neste aspecto, para além do tempo sem tempo da rádio comercial, podemos pensá-las a partir de outras dimensões da memória que não são as do tempo ordinário das rádios comerciais.

Estamos falando do tempo da memória que se coloca nas entrelinhas das rotinas das enunciações diárias do espetáculo midiático. Desta maneira, pensamos a linguagem radiofônica para além do meio, ainda que esta mídia nos ofereça muitas possiblidades para se conversar, para se realizar práticas comunicativas.

\section{Finalmente, as audiografias radiofônicas}

Dito tudo isto, voltamos para nossa proposta. Esta experiência propõe um caminho para a criação de arquivos sonoros, que chamamos de Audiografias textos históricos que têm com suporte os arquivos sonoros e a linguagem radiofônica. Os áudios, gravados e editados a partir desta perspectiva, foram distribuídos

1 Para ver como as mídias vão se transformando e ganhando novas funções indicamos a leitura do texto de Umberto Eco chamado Muito Além da Internet. Acesso em: http://www1.folha.uol.com.br/fsp/mais/fs1412200304.htm

2 Alguns sites como o UStream são sistemas de streaming que permitem a transmissão direta de vídeo e de áudio. Estes mesmos arquivos podem ser gravados e disponibilizados como fonogramas ou vídeos. 
Artigos

através de redes virtualizadas na internet. Para fazer tal proposta, criamos uma página no Facebook que foi chamada de Paisagens Históricas

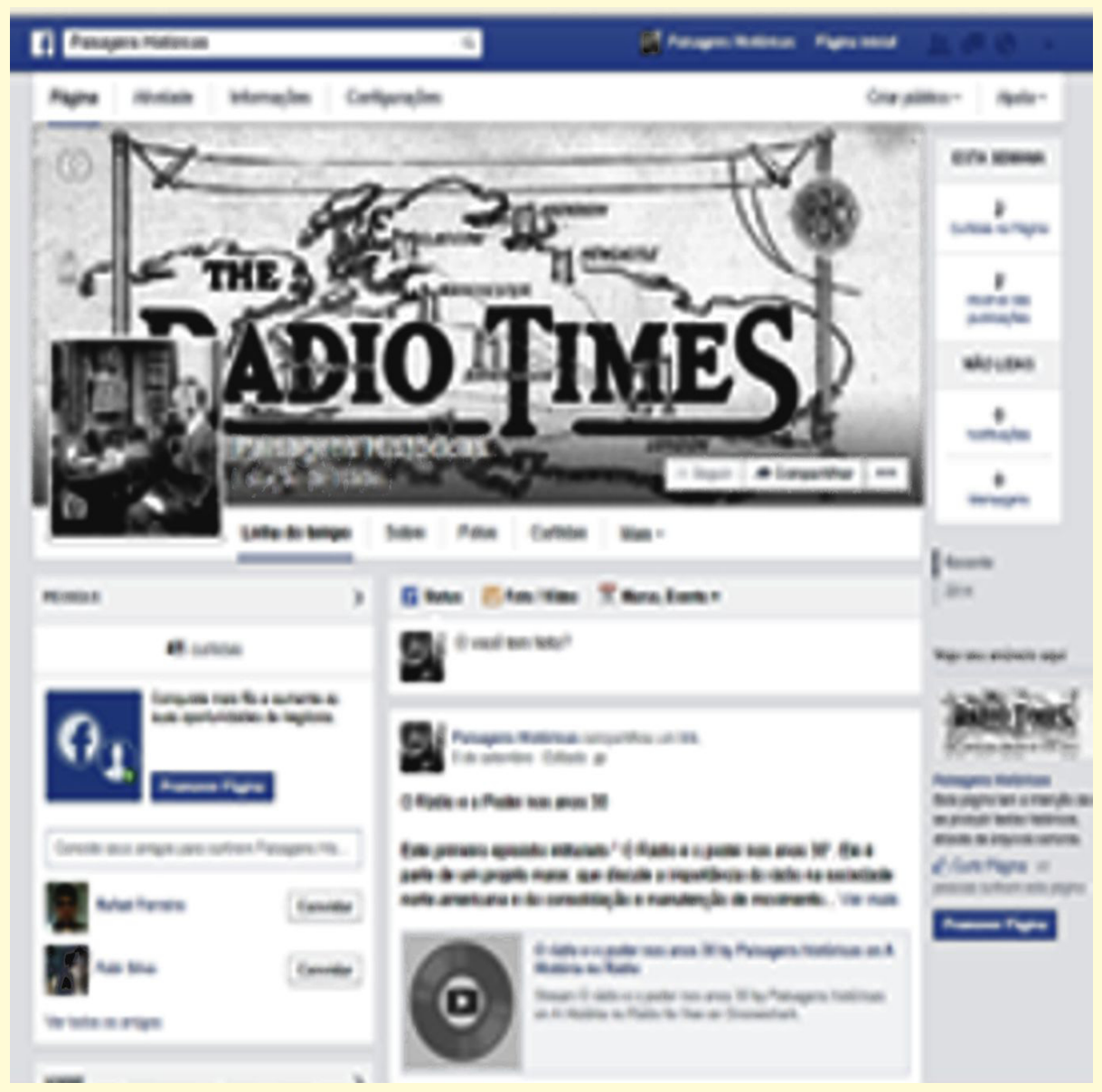

Reprodução da página do Facebook.

Pretende-se que esta página atinja públicos mais amplos e que possa alimentar a conversa entre os mais variados interlocutores. Desta maneira, o foco do trabalho é pensar nas audiências, tal como tem sido a preocupação dos historiadores de História Pública.

Nossa produção fez a seguinte pergunta, então: a História pode ser construída através de sons? Como construir uma narrativa histórica através de registros sonoros?

Tomamos os áudios históricos como fontes e também como objetos de pesquisa do historiador. Não os pensamos como acessórios ilustrativos, mas como possibilidades efetivas para se produzir pesquisas históricas.

O desafio é utilizar a oralidade mediada e a linguagem do rádio, suporte que revolucionou o século XX e que vem se transformando ao longo deste em virtude das Tecnologias da Informação e da Comunicação, chamadas de TIC's. A internet e as redes virtuais modificam a relação entre aquele que produz e aquele é o interlocutor. De ambos os lados do processo conversacional. As TICs são redes alimentadoras da comunicação e não somente da informação, são sociotécnicas, tal como pensa Castells. Para os historiadores, as 'TIC's reorganizam a produção do conhecimento científico e o fazer histórico, levantando desafios interessantes. As redes virtualizadas, a televisão, a digitalização dos periódicos científicos e o crescente número de sites relacionados à História denotam esta mudança.

As Audiografias estão inseridas neste contexto. Das contradições das indústrias culturais nascem possibilidades efetivas de se fazer um conhecimento mais autônomo em relação ao mercado de bens simbólicos.

Foi nesta perspectiva que propusemos nosso primeiro episódio intitulado "O Rádio e o poder nos anos 30”. Ele discute a importância do rádio na sociedade norte-americana e a consolidação e manutenção de movimentos totalitários na Europa, neste período. Propusemos trabalhar comparativamente estes contextos. Utilizamos vários tipos de fontes, disponibilizados em vários espaços, como o acervo digitalizado da 
$\underline{\mathrm{BBC}}$, um amplo acervo digitalizado que foi usado aqui como fontes. Também buscamos outras fontes para a pesquisa, como banco de dados (como o soundboard), mas também outros bancos importantes como a biblioteca digital Internet Archive e o European History Primary Sources (EHPS)

De tal modo que nos interessou pensar os contextos em que se produziram as falas e, principalmente, a maneira com esta produção é recebida. A fala de Goebells ou a da Orson Wells foram contextualizadas e costuradas pelos contextos em que foram produzidas. A novidade aqui ficaria em trazer os áudios como fontes primárias e editá-las, dando sentido a um texto no formato deste suporte. Aí está o desafio. Pensar sempre na perspectiva que "as intenções imediatas, estratégias e táticas dos comunicadores precisam estar sempre relacionadas ao contexto nas quais elas operam”. (Burke, 2004)

\section{Considerações finais}

A História Pública quer produzir escritas históricas e fazer comunicação. Mas temos que pensar no significado deste movimento, tendo em vista o ponto de vista, a maneira como vai ser produzido pelo Historiador.

Para isto fomos buscar no paradigma relacional uma maneira de ver a comunicação do homem através das suas práticas comunicativas, das conversas entre os vários agentes que produzem a cultura e, no nosso caso, nas várias temporalidades. A História, entre as práticas e as representações, é terreno fértil para a produção de novas escritas, mediadores comunicacionais.

A linguagem do rádio, por exemplo, permite realizar este movimento, ao alimentar a fantasia, a imaginação através dos sons. O rádio comercial faz parte de um sistema midiático e é uma indústria. No entanto, ele não deixa de realizar uma conversa, de estabelecer interações entre os agentes da comunicação. Partimos desta sua característica para escrever a História através dos sons.

Por outro lado as TIC's modificaram substancialmente estes mediações, fazendo conversar muitos com muitos pela primeira vez na história. É neste contexto que estamos propondo as audiografias, que tem como base as chamadas videografias, que também propõem uma nova maneira de se produzir as escritas históricas por meio da escrita audiovisual.

Apresentamos aqui, finalmente, uma primeira proposta intitulada "O Rádio e o Poder nos anos 30" disponibilizada na internet e distribuída através das redes virtualizadas, como na página criada para o projeto, chamada de Paisagens Sonoras.

\section{Referências}

BARBOSA, Marinalva. Jornalistas, "senhores da memória"? In: CONGRESSO BRASILEIRO DE CIÊNCIAS DA COMUNICAÇÃO, 2004 . Rio de Janeiro. Anais... São Paulo: Intercom, 2004. CD-ROM.. http:// hdl.handle.net/1904/1248.

BRAGA. José Luis. Constituição do Campo da Comunicaşão: Constitution of the Communication Field. Verso e Reverso, XXV(58):62-77, janeiro-abril 2011.

BURKE, Peter. Uma História Social da Mídia: De Gutemberg a Internet. Rio de Janeiro: Jorge Zahar, ed. 2004.

CASTELLS, Manuel. Sociedade em Rede: Economia, sociedade e Cultura. Vol. 1. São Paulo: Editora Paz e Terra, 2002.

CHARAUDEAU, Patrick. Discurso das Mídias. São Paulo: Contexto, 2006.

LIDDINGTON, Jill. O que é História Pública: Os públicos e seus passados. In: Introdução à História Pública. Juniele Rabelo, Marta Gouveia de Oliveira Rovai.(org). São Paulo: Letra e Voz, 2011

MAUAD, Ana Maria. Fontes de memória e o conceito de escrita videográfica: a propósito da fatura do texto videográfico. 
Artigos

Milton Guran em três tempos (LABHOI, 2010)* História Oral, v. 13, n. 1, p. 141-151, jan.-jun. 2010. MEDITSCH, Eduardo. O Rádio na Era da Informação. Coimbra: Minerva, 1999.

PRATA, Nair. Webradio: Novos gêneros, novas formas de interação. Florianópolis: Insular, 2009.

PRIMO. Alex Primo. Interação mútua e interação reativa: Uma proposta de estudo. Congresso Brasileiro de Ciências da Comunicação N. 21. Recife: Intercom, 1998. Acesso em http://hdl.handle.net/10183/431

RABELO. Juniele. ROVAI, Marta Gouveia de Oliveira. Introdução à História Pública. São Paulo: Letra e Voz, 2011.

THOMPSON, John. Mídia e Modernidade. Uma teoria social da mídia. Petrópolis: Vozes, 2001.

VEIGA FRANÇA, V. Paradigmas da Comunicação: conhecer o quê?. Ciberlegenda. Niterói: Revista do Programa de Pós-graduação em Comunicação da UFF. 2001. Disponível em: < $\underline{\text { http://www.uff.br/ciberlegenda/ }}$ ojs/index.php/revista/article/view/314/195> . Acesso em: 23 Out. 2014. 